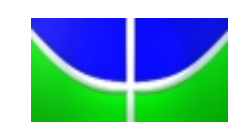

UNIVERSIDADE DE BRASÍLIA

Instituto de Relações Internacionais

\title{
Rompendo a rivalidade: aproximação das políticas nucleares de Brasil e Argentina
}

\author{
LAUREN LISIEUX MEDEIROS DE GODOI
}

Trabalho de Conclusão do Curso de Relações Internacionais para a Universidade de Brasília, apresentado como requisito parcial à obtenção do título de Especialista em Relações Internacionais.

Orientador: Prof. Dr. EIITI SATO

Brasília - DF

Abril/2010 


\title{
RESUMO
}

O presente trabalho visa a analisar o desenvolvimento das políticas nucleares do Brasil e da Argentina que, em dado momento, decidiram pela cooperação e pela ampla troca de informação. O trabalho aborda o desenvolvimento de seus programas nucleares e o processo de integração em questões de energia atômica, que culminou com a assinatura de um acordo Quadripartite prevendo o estabelecimento de uma agência bilateral (a Agência Brasileiro-Argentina de Contabilidade e Controle de Materiais Nucleares - ABACC) em harmonia com a Agência Internacional de Energia Atômica (AIEA). Tal acordo representou a adesão plena da Argentina e do Brasil ao regime de não-proliferação e suas salvaguardas internacionais, processo este posteriormente aprofundado com a ratificação de um acordo regional (o Tratado de Tlatelolco) e do Tratado de Não Proliferação (TNP). Apesar de tudo a trajetória dos dois programas de desenvolvimento nuclear seguiram caminhos distintos.

\begin{abstract}
The present essay aims to present and analyze the nuclear technology development programs of Argentina and Brazil. In the 1980s both countries decided to cooperate with each other in nuclear technology development signing a broad treaty which established in cooperation with AIEA an Argentinian-Brazilian Agency for Control and Accountability of Atomic Materials (ABACC). To a large extent such a step meant the adoption of the non-proliferation principle in atomic matters even before the signature and ratification of the Tlatelolco and the NPT Treaties. Nevertheless, each program has followed distinct paths and the achievements were also different.
\end{abstract}




\section{SUMÁRIO}

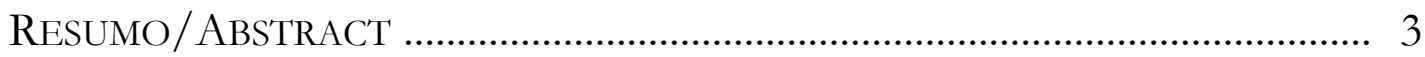

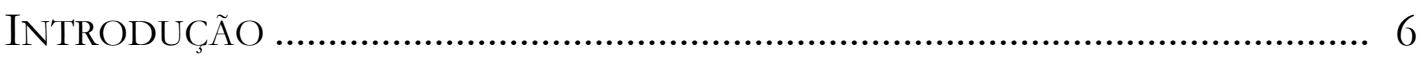

Capítulo 1 - COOPERAÇÃO INTERNACIONAL E REGIMES

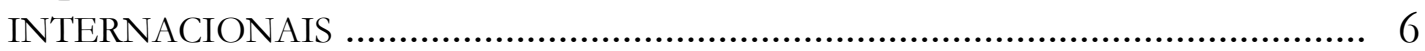

Cooperação Internacional....................................................................... 6

Cooperação e Segurança Internacional ................................................. 10

Tratado de Não-Proliferação de Armas Nucleares (TNP) ........................ 10

Tratado para a Proibição de Armas Nucleares na América Latina e no Carïbe (Tratado de Tlatelolco) ......................................................... 13

Agência Internacional de Energia Atômica (AIE A) .................................. 15

Zona de Paz e Cooperação no Atlântico Sul (ZOPACAS) ....................... 16

Capítulo 2- Histórico dOS PROGRAMAS NUCLEARES DO BRASIL E DA

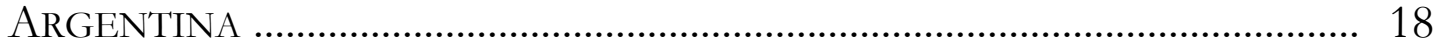

O programa nuclear brasileiro ............................................................... 18

O programa nuclear argentino ............................................................... 26

Capítulo 3- AProXimaÇÃO NA POLÍTICA NUClEAR DA ARGENTINA E DO

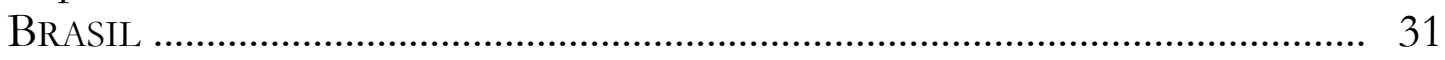

O Acordo Quadripartite ..................................................................... 39

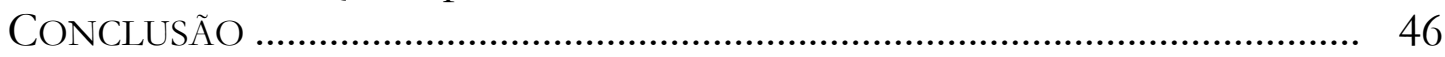

REFERÊNCIAS BIBLIOGRÁFICAS .............................................................. 50 


\section{Introdução}

A era nuclear tem sua gênese marcada pelo triste evento das detonações nucleares em Hiroshima e Nagasaki, ao final da Segunda Guerra Mundial. Desde então, diversas têm sido as tentativas de construção de um regime internacional de proscrição das armas nucleares e de não-proliferação de tecnologia nuclear.

A primeira tentativa de estabelecimento de restrições à proliferação data do pós-guerra imediato com o Plano Baruch, de 1946. ${ }^{1}$ À época apenas os Estados Unidos haviam demonstrado serem detentores da tecnologia nuclear e, no contexto da guerra fria que começava a ganhar forma, a União Soviética se recusou aderir à iniciativa e, ainda nos fins da década de 1940 realizou testes revelando ao mundo que também possuía conhecimento e tecnologia para a produção de armas nucleares Com o Tratado de Não-Proliferação (TNP), em 1967, as cinco grandes potências que haviam desenvolvido arsenais nucleares (a saber, EUA, URSS, Reino Unido, China e França) tentaram impedir que outros países as fabricassem. A idéia baseou-se em uma barganha diplomática: os outros Estados abririam mão do acesso a essas armas em troca do desarmamento progressivo das grandes potências e do acesso à tecnologia nuclear para fins pacíficos. Ao longo tempo, a expectativa era de que o processo levaria à ampla disseminação da tecnologia nuclear para fins pacíficos e ao banimento completo de arsenais nucleares.

Mais de 50 anos se passaram desde os ataques a Hiroshima e Nagasaki e, embora não haja ocorrido nenhum outro caso de emprego de armas nucleares, os arsenais existentes são suficientes para, literalmente, eliminar a

\footnotetext{
${ }^{1}$ O Plano Baruch foi apresentado em junho de 1946 ao United Nations Atomic Energy Commission propondo controlar a produção de armamentos nucleares e o uso dessa tecnologia para fins pacíficos. A rejeição do Plano levou a uma corrida frenética pelo desenvolvimento de armas nucleares ao longo da década de 1950.
} 
vida humana na terra enquanto, por outro lado, as tentativas de construir mecanismos de efetivo controle sobre materiais, instalações e pesquisas nucleares continuam pouco eficazes representando sérios riscos para a segurança e paz internacionais. É nesse complexo cenário da arena internacional que os países, de uma forma ou outra, vem tomando decisões sobre a questão nuclear. Para muitos países a posse de tecnologia nuclear representa, na visão de seus governantes, elemento de autonomia, independência e de novas oportunidades enquanto para outros significa ameaça e gastos improdutivos. Esse quadro se afigura mais dramático para alguns países e regiões enquanto para regiões como a América do Sul a questão nuclear até o momento nunca ocupou o foco das atenções na política externa dos países.

O presente trabalho ambiciona analisar a política nuclear brasileira, bem como o processo de aproximação do País com a vizinha e tradicional rival Argentina, durante o desenvolvimento dos respectivos programas nucleares. Nessa análise, e não poderia ser diferente, procurar-se-á suas principais raízes herdadas do passado, refletir sobre alguns impasses do presente e, na medida do possível, tentar vislumbrar tendências e possibilidades que o futuro pode reservar na relação entre as políticas de desenvolvimento nuclear entre os dois países, os quais contam com um histórico de rivalidade em vários campos rivalidade essa que, ao transbordar para o campo nuclear, poderia trazer conseqüências virtualmente trágicas para a região.

O presente trabalho não tem, obviamente, a pretensão de esgotar o tema. Devido às características da questão nuclear, em muitos aspectos a presente análise não poderia abarcar informações outras que não sejam de domínio público, e a maioria dos tópicos abordados continua sendo alvo de controvérsia, o que dificulta, mas não impede, uma análise desapaixonada do tema. 


\section{CAPÍtulo 1 \\ Cooperação internacional e regimes internacionais}

\section{COOPERAÇÃO INTERNACIONAL}

A Cooperação Internacional é o mecanismo pelo qual um país ou uma instituição promove o intercâmbio de informação e experiências com vistas à busca de objetivos comuns que podem ser compartilhados. Em termos operacionais há o intercâmbio de conhecimento técnico, científico, tecnológico e cultural, mediante a implementação de programas e projetos com outros países ou organismos internacionais. A cooperação pode ser técnica, tecnológica ou financeira. ${ }^{2}$

Temas de cooperação estão sempre relacionados à coordenação de políticas em torno de objetivos cujos resultados podem ser, de alguma forma, compartilhados. Seja através de concordância de interesses ou mesmo através de um ator em condições de prover os meios para tornar efetiva a cooperação, como são os casos de organizações internacionais que, de muitas formas, podem servir de catalisadores do esforço de cooperação. O fato é que a cooperação em suas variadas formas tornou-se um importante componente da agenda internacional. Isso se dá por fatores múltiplos, porém ressalta-se a sua importância quando os temas em questão envolvem relações de poder e e a implementação de interesses considerados centrais pelos Estados.

A cooperação internacional pode ser harmoniosa, por meio de alinhamento de interesses devido a objetivos comuns, ou conflituosa quando se configuram divergências acerca do que genericamente se tem identificado como "de interesse estratégico". As alianças no caso de guerra constituem os

${ }^{2}$ http://www.anvisa.gov.br/rel/cooperacao.htm 
casos mais dramáticos de "cooperação conflituosa". As teorias de Relações Internacionais, em larga medida, são tentativas de interpretar através de diferentes perspectivas os potenciais das muitas iniciativas de cooperação.

A interdependência complexa é uma dessas abordagens teóricas que traz a cooperação como fenômeno relevante e central para a interpretação os fenômenos internacionais. ${ }^{3}$ Trata-se de uma abordagem analítica derivada do liberalismo e considera os fenômenos ocorridos a partir da década de 1960 como principal fonte de pesquisa. A compreensão de tais fenômenos considera processos ligados ao conceito de globalização como agentes causadores e propõe o sistema internacional como uma rede de canais interconectados, seja através do comércio, das finanças e da tecnologia, como elementos formadores de uma verdadeira rede de interesses comuns. Para Keohane e Nye, tais fenômenos tornam os Estados mais sensíveis ou vulneráveis uns aos outros, o que vem a diminuir os efeitos da anarquia internacional e provocam aumento da cooperação, buscando produzir ganhos mútuos e diminuir prejuízos comuns.

Tais possibilidades e a grande quantidade de práticas cooperativas bem sucedidas entre os Estados têm provocado aumento significativo nos processos de cooperação no sistema internacional. Pode-se dizer que esse quadro também é em boa medida aplicável à questão nuclear: os custos dos investimentos em pesquisa podem ser compartilhados, o conhecimento também pode ser compartilhado e, talvez mais importante, por se tratar de tema bastante sensível, a cooperação pode reduzir as desconfianças e tensões beneficiando, inclusive, outras instâncias de cooperação entre países. Pode-se dizer que no caso das relações Brasil-Argentina em questões de desenvolvimento de tecnologia nuclear vem obedecendo essa lógica.

\footnotetext{
${ }^{3}$ KEOHANE, Robert O.; NYE, Joseph S. "Power and Interdependence. Nova Iorque: Longman, 2001.
} 


\section{CoOperaÇão E SEguranÇa INTERNACIONAL}

Embora haja múltiplos conceitos de segurança internacional, a compreensão que pauta este trabalho refere-se a um sentido amplo, onde compreende a um conjunto de medidas e procedimentos adotados no sentido da proteção de lugares e pessoas, seja orientado a um determinado Estado ou a um conjunto de Estados.

Robert Jervis ${ }^{4}$ tratou da problemática da transposição da teoria dos regimes para o contexto da segurança internacional. A área da segurança é tida como uma arena de trato sensível, onde uma competição irrestrita pode levar a uma situação em que todos os atores saiam perdendo. Dessa forma, a cooperação é necessária no sentido de maximizar ganhos e minimizar os riscos e os potenciais focos de tensão. No entanto, regimes nessa esfera são particularmente difíceis uma vez que há sempre o receio de que haja violação de algum entendimento havendo, portanto, um forte incentivo para que os Estados ajam de forma individualista, unilateral. Além disso, o produto de uma iniciativa ofensiva se confunde com iniciativas classificadas como de defesa: o investimento em armamento. Essa característica peculiar às questões de segurança conduz a uma inevitável tendência que, facilmente, pode levar a uma corrida armamentista. Com efeito, quando um Estado pratica uma ação defensiva, a mesma pode ser interpretada como uma iniciativa ofensiva, levando os outros Estados a se armarem também. Dependendo de como são manejadas as relações externas, a atmosfera pode tornar-se ainda mais sensível e incerta e, em se tratando de segurança, as perdas tendem a ser mais relevantes e críticas do que em outros canais de relações entre os Estados como comércio e investimentos.

\footnotetext{
${ }^{4}$ JERVIS, Robert. "Realism, Neoliberalism and Cooperation". International Security Ithaca: Cornell University Press, 1983.
} 
Assim sendo, a cooperação torna-se indispensável, muito embora não seja uma medida suficiente na maioria dos casos. Na visão do que se convencionou identificar como realismo defensivo, o caráter anárquico ${ }^{5}$ do sistema internacional conduz os temas de segurança a uma prioridade inquestionável dos Estados. O que pode resultar em um fenômeno conhecido como "dilema da segurança". De acordo com $\mathrm{Nye}^{6}$, "nenhum Estado age por raiva ou orgulho, mas pelo medo causado pela percepção de ameaça do crescimento do outro. Afinal, a construção de defesas é uma resposta racional à percepção de uma ameaça." Enquanto alguns Estados procuram defender seu povo e território, outros buscam aumentar seu prestígio ou mesmo sua capacidade de influir no cenário internacional. Mais especificamente, tratandose da área nuclear, Kenneth $\mathrm{Waltz}^{7}$ sugere até uma possível estabilidade por meio da proliferação de armas. Conforme essa interpretação, uma vez que armar-se é uma tendência inevitável e que, havendo uma proliferação horizontal (disseminação para mais Estados), a estabilidade poderia ser garantida através do equilíbrio de poder entre as potências nucleares. Se formos tomar o que ocorreu nas seis décadas após a Segunda Guerra Mundial, essa hipótese não parece nada despropositada já que nesse período não houve confrontação militar entre as grandes potências e também não houve recurso ao emprego de armas nucleares.

No caso de Brasil e Argentina, o desenvolvimento nuclear foi em larga medida voltado para fins pacíficos e a escala de seus programas de desenvolvimento nuclear jamais atingiram níveis significativos para ameaçar seriamente o equilíbrio regional em matéria de segurança. Ainda assim, a sensibilidade do tema gera tensões e, ainda que não seja suficientemente eficaz, a cooperação na área de segurança é uma medida atenuante dos possíveis

\footnotetext{
${ }^{5}$ Conceito de Hedley Bull em "A Sociedade Anárquica".

${ }^{6}$ NYE, Joseph. "The Paradoxo f Amercian Power: Why the World's Only Superpower Can't Go It Alone. Oxford and New York: Oxford University Press, 2003.

${ }^{7}$ Kenneth Waltz, 1981.
} 
efeitos da questão do desenvolvimento de capacidade nuclear. $\mathrm{O}$ ambiente de cooperação entre Brasil e Argentina pode ser resumido por meio de tratados e instituições que são descritos de forma breve a seguir.

\section{O Tratado de Não-Proliferação de Armas Nucleares (TNP)}

Firmado no primeiro dia de julho de 1968, entrou em vigor em 5 de março de 1970. Nos primeiros vinte e cinco anos de vigência, foi objeto de cinco conferências, as quais ocorreram a cada cinco anos a partir de 1975. Na última em conferência prevista no texto original, realizada em 1995, os Estados signatários decidiram que o Tratado deveria continuar em vigor indefinidamente. Por sua aceitação internacional e abrangência em termos normativos, é considerado a pedra fundamental do regime internacional de não-proliferação nuclear.

Seu texto traz obrigações tanto para os Estados nuclearmente armados quanto para os que não possuem arsenal nuclear. Para os primeiros, obriga-se a não efetuar transferência, para qualquer recipiendário, de armas nucleares ou induzir qualquer Estado não nuclearmente armado a fabricá-los ou adquiri-los de outras maneiras. Para os Estados não-nucleares, por sua vez, há o compromisso de não receber, de qualquer procedência, a transferência de quaisquer armas nucleares ou outros artefatos nucleares explosivos, e não fabricá-los ou adquiri-los de outros modos. Além disso, as obrigações para todos os países membros consistem em: facilitar e participar na troca de equipamentos, materiais e informações científicas e tecnológicas para o uso pacífico de energia nuclear; e procurar de boa fé negociar medidas efetivas relacionadas ao fim da corrida de armas nucleares, ao desarmamento nuclear e a um tratado sobre o desarmamento geral e completo sob estrito e efetivo controle internacional. 
Sobre o problema da verificação, este acordo dispõe que os países não nuclearmente armados (chamados NNWS - Non-Nuclear Weapons States) concluirão acordos com a Agência Internacional de Energia Atômica (AIEA) dispondo sobre a aplicação de salvaguardas a todas as fontes ou materiais físseis especiais em todas as atividades nucleares pacíficas no território de tais Estados. Tais acordos serão concluídos com a AIEA, individualmente ou em conjunto com outros Estados.

Outros dispositivos do TNP dizem respeito ao direito de qualquer grupo de Estados de concluir tratados e acordos regionais que assegurem a ausência de armas nucleares em seus respectivos territórios e a convocação de conferências de revisão a cada cinco anos.

Desde sua assinatura, o TNP vem recebendo sucessivas adesões. Em 1975, após sua entrada em vigor, com 40 ratificações. Em 1988, eram 130 Estados signatários. Em 1992, o TNP contou com a significativa adesão da China e da França, potências nucleares e membros permanentes do Conselho de Segurança da ONU. Ainda na primeira metade da década de 90, países que haviam buscado no passado capacitação nuclear sem submeter-se ao TNP, como África do Sul, Argélia, Argentina e Chile, aderiram ao tratado. Com a adesão brasileira, o número de Estados-parte chegou a 187, abarcando quase a totalidade da comunidade internacional. Atualmente, o número de ratificações está na ordem de 189 países. Apenas Índia, Israel e Paquistão (países detentores de armas atômicas) mantêm-se fora do tratado, enquanto a Coréia do Norte, em um perigoso precedente, tornou-se o primeiro Estado a retirar-se do TNP, em 2003.

Com o fim da tensão desenvolvida durante a Guerra Fria, ocorreu uma redução dos arsenais nucleares, mas as perspectivas de efetivo desarmamento, ainda que gradual, continuaram remotas. Em 1995, foi realizada uma conferência para decidir sobre o futuro do tratado. As opções para os 
Estados-parte eram: 1) tornar o tratado permanente (extensão indefinida, posição defendida pelos EUA e pela maioria dos países ocidentais, além da maioria dos países do Leste europeu, desejosos de ingressarem na União Européia, na Organização do Tratado do Atlântico Norte - OTAN - ou em ambas); 2) estendê-lo por um ou mais períodos definidos, condicionando a extensão do Tratado a compromissos por parte das potências nucleares no campo do desarmamento nuclear (opção defendida pelo grupo dos países nãoalinhados - o qual ainda exigia renovadas pressões sobre Israel em razão de sua não adesão ao tratado); 3) uma terceira opção a ser considerada seria simplesmente encerrar o tratado. Depois de meses de acirrados debates, chegou-se a três decisões interligadas: extensão indefinida do tratado, criação de um grupo de Princípios e Objetivos para a Não-Proliferação e o Desarmamento Nuclear e o fortalecimento do processo de revisão do tratado.

Nos encontros do Comitê Preparativo (PrepCom) de 1997, 1998 e 1999, os Estados nuclearmente armados, por variadas razões (Nuclear Weapons States - NWS) bloquearam as tentativas de resolução sobre desarmamento. No PrepCom de 1998, por exemplo, os NWS rejeitaram uma proposta de declaração do Canadá conclamando os Estados-parte a assinar e ratificar o Tratado para o Banimento Completo de Testes Nucleares (CTBT). Cada potência nuclear tinha suas próprias razões para rejeitar essa proposta, no entanto, como elemento comum estava o fato de que nessa esfera o caráter anárquico do meio internacional se manifesta de modo mais evidente e o abandono dos testes significaria o congelamento da superioridade tecnológica de algumas potências.

Apesar da ausência de consenso nos encontros preparatórios, a Conferência de Revisão de 2000 trouxe surpreendentes e inéditos resultados no campo de não-proliferação e desarmamento. Vale destacar o papel da Coalizão da Nova Agenda - com participação ativa do Brasil, já membro pleno do TNP 
- que assumiu a liderança no processo de negociação direta com os NWS. O documento final da conferência trouxe uma série de avanços, os quais podem se destacar: foi mencionada, pela primeira vez, os nomes dos Estados que não fazem parte do Tratado conclamando especificamente Índia, Israel e Paquistão a aderirem ao Tratado como NNWS; os NWS concordaram em incluir no documento uma ênfase na "eliminação total" de arsenais por meio de passos progressivos, tais como a proibição da produção de material físsil, moratória de testes nucleares enquanto o CTBT não entra em vigor. $O$ documento conclamava ainda a redução do papel das armas nucleares nas políticas de segurança dos países, uma maior transparência em relação à capacidade nuclear dos Estados-parte e o fortalecimento dos mecanismos de avaliação do Tratado, com reuniões preparatórias nos três anos precedentes às Conferências de avaliação qüinqüenais.

Há ainda a determinação no sentido de que as Conferências devem avaliar tanto o período passado quanto traçar uma série de objetivos para o futuro. A "resolução sobre o Oriente Médio" também faz parte das decisões adotadas na Conferência de 1995. Mesmo sem mencionar diretamente Israel, a resolução destaca as preocupações com a existência de um Estado não-parte do Tratado na região e a operação por esse país de instalações nucleares que não estão sujeitas aos mecanismos de verificação e às salvaguardas. Vale notar que, apesar do momentâneo otimismo que trouxe em relação ao futuro, muitas das medidas foram definidas vagamente e não foram previstos prazos para que ações efetivas fossem concretizadas.

\section{Tratado para a Proibição de Armas Nucleares na América Latina e no Caribe (Tratado de Tlatelolco)}

Firmado em 14 de fevereiro de 1967, esse tratado entrou em vigor em 25 de abril de 1969, com natureza permanente, ou seja, com sua duração indefinida. As obrigações dispostas no tratado incluem: proibição e prevenção 
na região (a) de testes, uso, fabricação, produção e aquisição, por quaisquer meios, de qualquer arma nuclear, pelas próprias partes, direta ou indiretamente, ou representadas por outrem, ou de qualquer outra forma, (b) recebimento, armazenamento, instalação, distribuição, ou qualquer outra forma de possuir quaisquer armas nucleares, direta ou indiretamente, pelas próprias partes, ou representadas por outrem, ou de qualquer outro modo. As partes também se comprometem a absterem-se de encorajar ou autorizar, direta ou indiretamente, ou de qualquer outra forma, participar de teste, uso, fabricação, posse ou controle de armamento nuclear.

A zona de aplicação do tratado é zona especificada em seu título além de vastos setores dos Oceanos Pacífico e Atlântico. A verificação é feita por meio de acordos multilaterais ou bilaterais com a AIEA para aplicação de salvaguardas às atividades nucleares de países integrantes do tratado.

Esse documento ainda possui dois importantes Protocolos Adicionais, que seriam adotados por outras ZLANs (Zonas Livres de Armas Nucleares) criadas posteriormente. Pelo Protocolo I, Estados que têm responsabilidade de jure ou de facto sobre territórios na região de abrangência do Tratado (França, Países Baixos, Reino Unido e Estados Unidos) comprometem-se a aplicar o estatuto de desnuclearização a tais territórios. Pelo Protocolo II, as cinco potências nucleares do TNP comprometem-se a não utilizar armas nucleares contra Estados-parte do Tratado. ${ }^{8}$

Entre os princípios do tratado que foram de grande relevância para a política externa brasileira, principalmente depois de 1964, estão: o uso pacífico da energia nuclear como base do tratado; a distinção entre armas nucleares (artigo 5) e explosões para fins pacíficos (artigo 18), cujo direito de realização

\footnotetext{
8 Os Estados Unidos ratificaram o Protocolo II do Tratado com reservas. A principal delas refere-se ao artigo 3 do Protocolo: os EUA se reservam o direito de uso de armas nucleares no caso de um eventual ataque armado ao seu território perpetrado por um Estado-parte de Tlatelolco auxiliado por uma potência nuclear.
} 
fica assegurado às partes; a previsão de garantias formais de todas as potências nucleares e extra-continentais de respeito ao estatuto de desnuclearização e de não-uso de armas nucleares contra os países da região (artigo 28 e Protocolos); a entrada em vigor para cada Parte sujeita à universalidade da participação ou à dispensa expressa desse requisito (artigo 28-1); a elaboração do conceito de potência nuclear podendo abranger países que no futuro viessem a possuir armas nucleares, caso em que a vigência do tratado poderia ser temporariamente suspensa até que estes firmassem o Protocolo II (artigo 28-4). Com a conclusão, em 1966, do processo de ratificação do Tratado de Tlatelolco por São Cristóvão e Névis e pela Guiana, o instrumento entrou em vigor para todos os países da América Latina e do Caribe, exceto para Cuba.

As origens do tratado remontam a 1958, quando a Costa Rica apresentou à Organização dos Estados Americanos (OEA) proposta de que os países latino-americanos não fabricassem armas nucleares ou as adquirissem das potências nucleares. A idéia não prosperou na OEA, mas ganhou força em função do episódio da crise dos mísseis soviéticos em Cuba, em 1962. Durante a XVII Assembléia Geral da ONU, em 15 de novembro de 1962, o Brasil apresentou a primeira proposta de criação de uma Zona Livre de Armas Nucleares (ZLAN) na América Latina, mas tornou-se menos favorável à idéia com a ascensão dos militares em abril de 1964. A partir de 1963, o México assumiu a liderança do processo negociador, que culminou na criação do Tratado.

\section{Agência Internacional de Energia Atômica (AIEA)}

Criada em 1957, a AIEA tem como funções promover e ajudar a pesquisa e o desenvolvimento para aplicação pacífica e prática do uso da energia atômica; estabelecer e administrar salvaguardas destinadas a assegurar que nenhuma atividade auxiliada pela Agência venha a ser usada para fins militares; aplicar salvaguardas às atividades relevantes a pedido de países- 
membros; aplicar, de acordo com o TNP e outros tratados internacionais, salvaguardas mandatórias e abrangentes para os NNWS integrantes de tais tratados. No desempenho de suas funções, a AIEA conduz suas atividades seguindo os princípios da ONU para promoção da paz e da cooperação entre os países. O sistema de salvaguardas é definido no artigo XII do Estatuto da AIEA, e nos documentos INFCIRC/66 (aplicável no caso de países que tenham concluído um acordo de salvaguardas) e INFCIRC/153.

\section{Zona de Paz e Cooperação no Atlântico Sul (ZOPACAS)}

Esse acordo surgiu a partir da proposta apresentada pelo Brasil em 1986, nas Nações Unidas. A iniciativa resultou na Resolução 41/11 da Assembléia Geral, que estabeleceu a Zona de Paz e Cooperação no Atlântico Sul. Aliado aos Tratados de Tlatelolco e Pelindaba, e à Comunidade dos Países de Língua Portuguesa, esse acordo regional busca a desnuclearização militar completa da região, a proteção do meio ambiente marinho e o combate ao tráfico de entorpecentes, além de procurar evitar o envolvimento da área em conflitos internacionais e fortalecer o papel dos países membros na condução dos assuntos relativos ao Atlântico Sul. Em 1996, o Brasil apresentou na I Comissão da Assembléia Geral da ONU projeto de resolução intitulado “O Hemisfério Sul e Áreas Adjacentes Livres de Armas Nucleares", com o objetivo de buscar o reconhecimento internacional do estatuto de desnuclearização militar dessa extensa região. O objetivo político principal do projeto foi o de valorizar o conceito de zona livre de armas nucleares (ZLAN). As potências nucleares ocidentais não aceitaram o projeto, que poderia limitar a liberdade de movimentar submarinos e navios nuclearmente armados nos mares do hemisfério sul.

Os tratados e instituições aqui apresentados, ainda que de maneira resumida, servem para proporcionar uma idéia acerca do contexto dentro do qual a aproximação e estabelecimento de um programa de cooperação entre o 
Brasil e a Argentina. Esse quadro também serve de cenário para se compreender a evolução dos programas de desenvolvimento da capacitação nuclear de Brasil e Argentina. Algumas motivações para a evolução da cooperação entre ambos no contexto dos anos 1980 estiveram associadas tanto a mudanças no cenário internacional e regional quanto a transformações no quadro econômico e político interno desses dois países. 


\section{CAPÍTUlO 2 \\ Histórico dos programas nucleares do Brasil e da Argentina}

\section{O PROGRAMA NUCLEAR BRASILEIRO}

Datam de 1934 os primeiros trabalhos brasileiros no campo da física nuclear, desenvolvidos, no início, na Faculdade de Filosofia, Ciências e Letras da Universidade de São Paulo (USP), com a colaboração de alguns cientistas estrangeiros que, ao longo da década de 1930, vieram para o Brasil. ${ }^{9}$ Aos poucos, pesquisadores de outros centros passaram a contribuir com a pesquisa das potencialidades da energia nuclear.

Nessa época, foram descobertas grandes jazidas de urânio natural no País. O governo brasileiro buscou controlar as exportações de minérios nucleares, estabeleceu reservas e estoques estratégicos e estimulou o desenvolvimento da tecnologia nuclear no setor. Foram feitas, inclusive, as primeiras tentativas de formulação de uma Política Nacional de Energia Nuclear.

Em 1951, foi criado o Conselho Nacional de Desenvolvimento Científico e Tecnológico (CNPq), que, entre suas funções mais importantes estava a de prestar apoio financeiro às pesquisas na área nuclear. Cinco anos mais tarde, em 1956, o CNPq foi substituído em tais incumbências, com a criação da Comissão Nacional de Energia Nuclear (CNEN). ${ }^{10}$

\footnotetext{
${ }^{9}$ Em 1925 Albert Eisntein esteve no Brasil. Embora sua visita tivesse sido muito rápida, despertou grande interesse para além da comunidade científica. Ver Alfredo Tiommo Tomalsquim, Einstein - O Viajante da Relatividade na América do Sul. Editora Vieira \&Lent, 2003.

10 Ver a Um Espaço para a Ciência - A Formação da Comunidade Cientifica no Brasil de autoria de Simon Schwartzman (MCT/CEE, Brasília, 2001).
} 
Entretanto, a falta de definição quanto a uma política nuclear resultou em um processo de discussão sobre opções distintas. De um lado, a opção nacionalista, de auto-suficiência, contra o monopólio externo, e a favor do desenvolvimento de tecnologia do urânio natural e da água pesada. Tal alternativa também incluía a construção de usinas e a fabricação dos reatores e do combustível. Do outro lado, existia a opção pelo acordo com países detentores de tecnologia nuclear, dessa forma internacionalizando a produção e o uso da tecnologia nuclear do País. Neste caso o padrão de desenvolvimento da tecnologia seria o do urânio enriquecido e da água leve.

Cervo \& Bueno mencionam os esforços brasileiros, à época, para obtenção de tecnologia nuclear, que envolviam negociações sigilosas:

$\mathrm{Na}$ busca de alternativa, já que os Estados Unidos não forneciam os equipamentos de que o Brasil julgava necessitar no campo no campo da energia atômica, o CNPq, presidido pelo Almirante Álvaro Alberto, sigilosamente, negociou a compra, por 80 mil dólares, em janeiro de 1954, de três ultracentrífugas para a separação de urânio 235 (U-235), de firmas particulares alemãs. O Brasil não as recebeu, em razão de a Alemanha, consoante o estatuto de ocupação das potências, não poder fabricá-las. Mesmo depois de finda a ocupação, em abril de 1955, a encomenda não foi entregue, por razões não suficientemente esclarecidas, podendo-se mesmo assim alinhar a não-definição, pelo $\mathrm{CNPq}$, da ciclagem dos motores que as acionariam e a ineficiência do material encomendado como possíveis explicações. ${ }^{11}$

Como mencionado anteriormente, não havia consenso dentro do governo sobre a melhor opção para o programa nuclear brasileiro:

Com referência à política atômica, percebe-se que não havia união de objetivos entre parte das Forças Armadas e o Executivo, principalmente ao tempo que João Neves da Fontoura ocupava a pasta do Exterior. Este tinha posições favoráveis à aproximação com os Estados Unidos. Houve também momentos de descompasso entre o $\mathrm{CNPq}$, criado em

${ }^{11}$ CERVO, Amado e BUENO, Clodoaldo. História da Politica Exterior do Brasil. Coleção "O Brasil e o Mundo". Editora UnB/IBRI. $2^{a}$ edição. Brasília, 2002, p. 282. 
1951, e a Comissão de Energia Atômica do Itamaraty. Assim, o intenso debate sobre o aproveitamento dos minerais atômicos que existiam no País refletia-se no próprio governo e no Congresso Nacional. Com a ascensão de Café Filho, acentuar-se-ia a diferença no modo de ver a questão atômica entre o CNPq e o Itamaraty. ${ }^{12}$

Como já mencionado, em meados de outubro de 1956, o CNPq foi substituído na função de executar a política nuclear, tarefa esta assumida pela recém-criada Comissão Nacional de Energia Nuclear (CNEN). Essa Comissão estabeleceu uma estreita colaboração com os Estados Unidos, no escopo do programa "Átomos para a Paz". Ainda assim, a criação da CNEN não significou um grande impulso imediato ao desenvolvimento da ciência e tecnologia nuclear, pois faltava coordenação entre os vários centros espalhados pelo País. Além disso, não havia políticas estruturadas de longo prazo. ${ }^{13}$ Com efeito, o governo de João Goulart (1961-64) não modificou a situação do programa nuclear brasileiro:

Na presidência João Goulart, pouco seria feito em termos do exercício do direito à nuclearização, salvo a tentativa não consumada de um acordo com a França para fornecimento de um reator de potência de urânio natural. A posição fluida, de virtual abstinência nesse terreno, coincidiria com forte dose de ativismo diplomático em favor do controle da corrida nuclear, dentro de cujo contexto, o Brasil indicaria a disposição de aceitar compromissos de não armamento nuclear, sem contrapartidas tecnológicas e independentemente das restrições que desses compromissos pudesse resultar para a aquisição de uma capacidade tecnológica nuclear para fins civis. ${ }^{14}$

Com os governos militares, houve uma paulatina tentativa de nacionalização da segurança, que teve reflexos no programa nuclear. O Brasil abandonava, deste modo, a idéia de segurança coletiva e manifestava o desejo

\footnotetext{
12 Idem, pp. 282-283.

13 WROBEL, Paulo. "A política nuclear brasileira”. In Sessenta Anos de Política Externa Brasileira 19301990: Vol. 4. NUPRI/USP. 2000, p.71.

14 BATISTA, Paulo Nogueira. "O acordo nuclear Brasil-República Federal da Alemanha”. In: Sessenta Anos de Politica Externa Brasileira 1930-1990: Vol. 4. NUPRI/USP. 2000, pp. 29-30.
} 
de alcançar uma rápida nuclearização - embora, como se alegava à época, com fins pacíficos. A primeira tentativa governamental explícita de estabelecer prioridade à área nuclear surgiu em 1967, quando da posse do presidente Artur da Costa e Silva. A opção de desenvolvimento endógeno do setor foi descartada, e o foco passou a ser a importação de tecnologia nuclear com eficiência comercialmente comprovada.

Basicamente, Costa e Silva vinculou o conceito de segurança ao de desenvolvimento, ao entender que a segurança não poderia depender da boa vontade de outras potências ou de sistemas de alianças. $\mathrm{Na}$ arena internacional, opôs-se ao Tratado de Não-Proliferação Nuclear (TNP), nos termos propostos pelos Estados Unidos e pela União Soviética, os quais consolidavam a desigualdade tecnológica. Para que esse Tratado recebesse a aceitação brasileira, duas eram as condições impostas: a garantia de acesso à tecnologia nuclear e a implementação de medidas efetivas de desarmamento por parte das potências nucleares. Posto que essas condições não eram atendidas, o País mantinha a posição refratária ao TNP. Por outro lado, em 9 de maio de 1967, o Brasil assinou o Tratado de Tlatelolco, que proscrevia as armas atômicas na América Latina - o qual deixava ambiguamente aberta a opção de serem realizadas explosões nucleares para "fins pacíficos".

No campo nuclear, buscava-se acelerar o desenvolvimento do programa nuclear nacional, não pela importação do produto final mas pela busca de tecnologia própria, embora sem sucesso. Nesse sentido, o Brasil assinou acordos nucleares com Israel (1966), França (1967), Espanha e Índia (ambos em 1968), Equador (1970) e Estados Unidos (1972, para garantir o fornecimento de urânio enriquecido destinado à usina de Angra); entretanto, nenhum deles resultava em transferência de tecnologia. ${ }^{15}$ Restava, portanto, apenas a opção de continuar a busca pela tecnologia do enriquecimento de

${ }^{15}$ CERVO e BUENO, op. cit., p. 405. 
urânio com a esperada ajuda externa. O Acordo de Cooperação para Usos Pacíficos de Energia Nuclear, firmado com os Estados Unidos em 1972, permitiu a construção de um reator de potência a urânio enriquecido - a primeira unidade da Central Nuclear Almirante Álvaro Alberto (Angra I).

Nesse quadro havia a percepção de que o Brasil permanecia carente de um programa nuclear autônomo: o combustível utilizado (urânio enriquecido) em Angra I seria comprado dos Estados Unidos, e, depois de utilizado, devolvido ao fornecedor, para separar o plutônio dos produtos da fissão. Todos os equipamentos e instalações - o reator de pesquisa do IPEN, o reator do CDTN e a usina de Angra I, comprada da Westinghouse, estavam sob salvaguardas do acordo trilateral AIEA/EUA/Brasil (INFCIRC/110). Em termos práticos, malgrado as tentativas em direção à autonomia, inicialmente institucionalizou-se uma situação de dependência às regras impostas pelos Estados Unidos, situação essa refletida nos sucessivos acordos bilaterais atômicos firmados entre 1940 e 1974. Dessa forma, o Brasil tornou-se dependente daquele país, o qual se tornou seu único fornecedor de urânio enriquecido.

Após a guerra do Yom Kippur e a conseqüente crise do petróleo, os EUA suspenderam a garantia do fornecimento de urânio para futuras usinas nucleares brasileiras. Tal situação gerou fortes questionamentos, no Brasil, acerca do relacionamento de dependência em relação aos EUA para o fornecimento de combustível nuclear:

Dois eventos em 1974 puseram fim à disposição do governo brasileiro aceitar aquele relacionamento. O primeiro foi a explosão pela Índia de um dispositivo nuclear. (...) O sucesso da Índia estimulou os militares brasileiros e argentinos a exigirem progresso mais rápido na aquisição de sua própria capacidade nuclear (com a implicação de que seria com o ciclo completo de combustível). (...) O segundo evento em 1974 foi o anúncio da Comissão de Energia Atômica dos Estados Unidos de que em virtude de sua limitada capacidade de 
processamento não podia mais garantir ao Brasil (e a outras nações) o atendimento de suas necessidades totais de urânio enriquecido. $^{16}$

A notícia foi divulgada em meio às negociações de um gigantesco contrato com a Westinghouse, que se comprometia a fornecer ao Brasil até 12 reatores, pelo valor de US\$ 10 bilhões. Quando os Estados Unidos retiraram a garantia do combustível as negociações desmoronaram.

A aparente facilidade com que os Estados Unidos revogaram seu compromisso parecia confirmar as sinistras previsões dos nacionalistas brasileiros (tanto de direita quanto de esquerda) que há muito criticavam a política do governo de indefinida dependência de uma fonte estrangeira para a obtenção do elemento crucial no ciclo de combustível nuclear. ${ }^{17}$

O governo Geisel definiu, em um quadro de aumento da demanda energética e de tentativa de nacionalização da segurança, um prazo de dez anos para que fosse construída uma verdadeira indústria nuclear. Para tanto, ficou definido que a melhor forma era um amplo acordo de cooperação com a República Federal da Alemanha, com a expectativa de transferência ao Brasil da tecnologia do ciclo completo do combustível, ciclo este que compreende desde a localização do minério e seu processamento, até a fabricação do elemento combustível que supre as centrais elétricas nucleares. Encerra-se este ciclo com o reprocessamento e o reaproveitamento do material físsil contido no combustível irradiado das usinas nucleares. O projeto de cooperação com a Alemanha sofreu enorme pressão por parte dos Estados Unidos:

De fato, tanto pela amplitude e profundidade quanto pelas dimensões industriais e financeiras, o acordo assinado em Bonn, em junho de 1975, constitui o mais importante instrumento de cooperação entre um país desenvolvido e um em desenvolvimento, sobretudo pelas questões de alta tecnologia que abrangia e pelas implicações políticas internacionais. Além de projetar a Alemanha Ocidental como fornecedora de equipamentos e serviços num mercado antes

\footnotetext{
${ }^{16}$ SKIDMORE, Thomas E. Brasil: de Castelo a Tancredo. Rio de Janeiro. Paz e Terra. 1988, p. 378.
}

${ }^{17}$ Idem. 
dominado pelos Estados Unidos, com modesta competição da França, da Inglaterra e do Canadá, o Acordo com o Brasil viabilizaria a execução do primeiro programa efetivo de utilização pacífica, em larga escala, de energia atômica por um país em desenvolvimento. (...) o Acordo teuto-brasileiro não poderia deixar de ter grande relevância tanto sobre a posição de nosso País no mundo e sobre a política externa brasileira quanto sobre a política internacional na questão central da não-proliferação de tecnologia nuclear para fins civis, entendida pelas potências nucleares como tendo inevitáveis derivações geopolíticas e de segurança. Para Brasília como para Bonn, o Acordo representaria, por isso mesmo, uma primeira grande manifestação de capacidade de atuação independente frente aos Estados Unidos num campo da mais alta prioridade. $^{18}$

Da mesma forma que o acordo com os Estados Unidos, todos os equipamentos e instalações provenientes da República Federal da Alemanha estavam sujeitos a estritas salvaguardas por meio de um acordo trilateral AIEA/Alemanha/Brasil (INFCIRC/237). Fundamentado nesse acordo, o programa nuclear brasileiro seria concretizado a partir da construção de um complexo de oito usinas nucleares para geração de energia elétrica e a construção de um complexo de usinas destinado ao ciclo de combustível nuclear, incluindo uma fábrica para enriquecimento de urânio em escala comercial, uma planta piloto de reprocessamento de plutônio e transferência da tecnologia de enriquecimento de urânio "jet nozzle". Entretanto, o programa sofreu atrasos na sua implementação e não atingiu seus objetivos iniciais.

A avaliação final é que não foram as pressões externas, apesar de fortes, que acabaram por solapar o ambicioso acordo com a Alemanha. Analistas entendem que esse acordo foi, antes, vítima do próprio gigantismo e de equívocos de planejamento. O acordo comprometia o País financeira e 
tecnicamente acima de sua capacidade, e acabou deixando como herança enormes e ociosas instalações industriais e caros equipamentos sem uso. ${ }^{19}$

No governo do presidente João Baptista Figueiredo surgiu um programa paralelo, quando ficou patente que o acordo nuclear entre Brasil e Alemanha não traria a tecnologia que os militares desejavam. Iniciado em 1977 e desenvolvido sem divulgação junto à sociedade civil, o referido programa paralelo buscava o domínio do ciclo de combustível nuclear. Chamado de "Projeto Solimões", o programa secreto de capacitação nuclear para fabricação da primeira arma nuclear teve duas versões, uma para a Força Aérea Brasileira e outra para o Exército Brasileiro, posteriormente unificados sob coordenação direta do Gabinete Militar da Presidência da República. A Marinha, por sua vez, deveria fabricar um reator de baixa potência (projeto Remo) e desenvolver a tecnologia de enriquecimento de urânio (projeto Ciclone), com o objetivo de desenvolver reatores e os demais equipamentos necessários para a propulsão para submarinos movidos a energia nuclear.

Com o fim da época dos governos militares, ocorreu uma reavaliação das metas do acordo nuclear com a Alemanha. Não obstante, os programas desenvolvidos pelos militares obtiveram resultados significativos em termos de desenvolvimento de tecnologia nuclear. Condenado pelo então presidente Fernando Collor, o programa paralelo teve sua estrutura redirecionada para pesquisas científicas sem fins militares. Em setembro de 1990, o presidente Collor lacrou simbolicamente, com duas pás de cal, uma perfuração no solo feita no início da década de 1980 pelo Ministério da Aeronáutica no campo de provas da Serra do Cachimbo. De acordo com a página eletrônica Global Security, "that act was made in an attempt to overcome US resistance to selling Brazil a super-computer for the development of space launch vehicles. The

${ }^{19}$ WROBEL (2000), op. cit., p.75. 
shaft had been public knowledge since 1986 and had been abandoned since $1987 " .20$

A condução do programa nuclear brasileiro é assim resumida por Paulo Roberto Campos Lemos:

Apesar da descontinuidade administrativa e de orientação política, e da crônica escassez de recursos, houve algumas realizações tecnológicas importantes, mais como reflexo dos esforços de grupos de pesquisadores e instituições, trabalhando de forma descoordenada, do que de méritos da política. Essas realizações ocorreram no âmbito do programa paralelo da Marinha. Foram eles, o desenvolvimento, nos anos 1980 e 1990, de um processo eficiente de enriquecimento isotópico por ultacentrifugação, com equipamentos inovadores desenvolvidos no Brasil, o desenvolvimento de tecnologia para fabricação de UF6, e o projeto de um reator de pequeno porte pela Marinha, destinado à propulsão de submarinos nucleares, mas adaptável à geração comercial de energia. Além disso, há que se assinalar o desenvolvimento de jazidas de minerais radioativos, que possibilitaram ao País deter, oficialmente, a sexta - provavelmente, a segunda - maior reserva de urânio do planeta.

Pouquíssima realizações para quase 60 anos, mas significativas se se leva em conta a falta de orientação estratégica e a crônica escassez de recursos destinados ao setor. $^{21}$

\section{O PROGRAMA NUCLEAR ARGENTINO}

Costuma-se dividir a história do desenvolvimento nuclear argentino em três fases. A primeira - de formação - que vai da criação da Comissão Nacional de Energia Atômica, em 1950, até 1958, em que a ênfase foi na implantação de infra-estrutura de pesquisa e na formação de recursos humanos. A segunda fase - de consolidação - foi caracterizada pela complementação dos objetivos da etapa anterior, e pelo desenvolvimento significativo das aplicações

\footnotetext{
${ }^{20}$ Global Security, <www.globalsecurity.org/wmd/world/brazil>. Acesso em 11/09/2009.

${ }^{21}$ LEMOS, Paulo R. Campos. Um programa nuclear conjunto Brasil-Argentina. Revista Insight, p. 92.
} 
da energia nuclear, que vai de 1959 a 1967. Finalmente, a terceira fase, que se estende de 1968 até os dias de hoje, em que se considera que o setor alcança sua maturidade, e o esforço passa a se concentrar no desenvolvimento de tecnologia, e na geração de energia.

Criada em 1950, a Comissão Nacional de Energia Atômica (CNEA) teve o apoio constante dos governos militares e civis que se alternaram no poder na Argentina por mais de três décadas. Durante os oito primeiros anos da década de 50, os argentinos iniciaram pesquisas com urânio, dando início também à formação de recursos humanos relacionados à área nuclear. $\mathrm{Na}$ década seguinte, foram desenvolvidas aplicações de radioisótopos, das fontes internas de radiação e da engenharia de reatores experimentais.

Entre 1967 e 1976, foram inaugurados os primeiros centros de produção de energia elétrica a partir de energia nuclear da América Latina. A central Atucha I (com capacidade de 340 MW), passou a operar em 1974, a qual, seguindo a decisão argentina, utilizava urânio natural como combustível e água pesada como moderador. A segunda central, Embalse (com capacidade de $600 \mathrm{MW}$ ), teve sua construção iniciada no mesmo ano. Esta central foi comprada do Canadá, país com o qual a Argentina assinara convênio assegurando ampla transferência de tecnologia nuclear. Entretanto, a explosão nuclear realizada pela Índia naquele ano resultou em um endurecimento da posição canadense sobre transferência desse tipo de tecnologia.

O período seguinte, de 1976 a 1983, foi marcado por um grande avanço do desenvolvimento do programa atômico argentino. Em 1980 foi iniciada a construção de Atucha II, com capacidade de 700 MW. Dois anos depois, os argentinos começaram a fabricar os elementos combustíveis para os reatores nucleares - até então o concentrado de urânio era enviado à Alemanha para que o processo fosse completado - e iniciaram a construção de uma fábrica de produção de água pesada, seguido pelas exportações de tecnologia 
nuclear. Em 1983, o país completava o ciclo do combustível, utilizando com sucesso a difusão gasosa, conseguindo assim realizar o processo de enriquecimento de urânio. ${ }^{22}$

O programa nuclear argentino teve características diferentes do programa nuclear brasileiro, o qual decidiu pela instalação de reatores alimentados por urânio enriquecido. O programa argentino optou pelo sistema que utiliza urânio natural e água pesada nos reatores. Comparativamente, esse tipo de reator proporcionou mais vantagens para a Argentina, que possui grandes reservas de urânio ${ }^{23}$ como, por exemplo, a possibilidade de se utilizar água pesada, que requer tecnologia menos sofisticada. Tecnicamente esse tipo de reator facilita o desenvolvimento de tecnologia endógena, oferecendo à indústria a possibilidade de se inserir no processo, projetando e produzindo os equipamentos necessários. Durante o funcionamento da usina, o urânio 238 sofre uma reação nuclear e transforma-se em plutônio 239, que tanto pode ser utilizado em outros reatores quanto para a produção de artefatos explosivos.

O modelo nuclear argentino, que possuía objetivos bem definidos, dava prioridade à auto-suficiência em recursos humanos, matéria-prima, equipamentos e tecnologia nuclear. De igual forma, buscava atingir o domínio completo do ciclo de urânio enriquecido, bem como suas alternativas, além de procurar obter o status internacional de fornecedor nuclear confiável. O desenvolvimento do programa argentino contou com auxílio canadense e alemão, com o fornecimento de reatores de potência. Além disso, a Suíça forneceu uma planta de água pesada, e a URSS contribuiu com outros equipamentos. A Argentina também teria alcançado capacidade de produzir

\footnotetext{
22 CARASALES, Julio Cesar. De rivales a socios: el processo de cooperación nuclear entre Argetina e Brasil. Buenos Aires. Nuevohacer. Grupo Editor Latinoamericano, 1997. p.19.

23 OLIVEIRA, Odete Maria de. Integração Nuclear Brasil-Argentina: uma estratégia compartilhada. Florianópolis. Editora da UFSC, 1996, p.171-172.
} 
plutônio, mas a fábrica piloto de separação foi abandonada em 1990, sem ter sido concluída. ${ }^{24}$

Durante a era Menem, quando se viveu na política externa uma fase de forte alinhamento argentino com os Estados Unidos, ocorreu um enfraquecimento do programa nuclear daquele país, agravado pelas posteriores crises políticas e econômicas, as quais fizeram-se sentir até o final de 2004. No final daquele ano, o editor-geral do jornal argentino Clarín lamentava o abandono do programa nuclear argentino e o compara ao brasileiro. Mesmo um pouco longa, vale reproduzir trecho daquele editorial:

Brasil está cerca de lograr plena autonomia en la producción de combustible nuclear, condicíon a la que se estima alcanzar em 2010. La noticia no sorprende porque los brasileños han mantenido uma actitud consistente en su programa de desarollo nuclear, a pesar de las presiones que está, y estuvo, sometido. (...) Argentina anunció en 1983 el domínio del ciclo completo para enriquecer el uranio, logrado en la planta de Pilcaniyeu. La comunicación del importante avance la recibió el presidente electo, Raúl Alfonsín, de manos del entonces titular de la Comisión Nacional de Energía Atômica, Carlos Castro Madero. La dictadura estaba em sus últimos estertores y uno de los secretod bien guardados fue develado pocos dias antes del retorno de la democracia.

En la década de los 90 se fijó uma política que afectó fuertemente el desarollo nuclear argentino. Antes de 1994, la CONEA tênia unos 5 mil científicos, técnicos y administrativos, manejaba las centrales de Atucha y Embalse y llegó a tener un presupuesto de 900 milliones de dólares. Hoy hay unos 2000 empleados: el resto fue a la empresa que controla las centrales o al retiro voluntario. No hay una política, según afirman fuentes de la Comisión, dirigida a incorporar nuevo personal. (...) La decisión política que tomo Menem tuvo como objetivo potenciar las relaciones con EE.UU. Aun cuando se dieron pasos correctos - la desactivación del proyecto Cóndor - las consecuencias para el desarollo nuclear argentino fueron muy serias. ${ }^{25}$

${ }^{24}$ Ver Global Security < www.globalsecurity.org/wmd/world/argentina>.

25 KIRSCHBAUM, Ricardo. Brasil, Argentina y el uranio. Jornal Clarín, 29 de novembro de 2004, editorial. 
Os melhores exemplos de realizações tecnológicas argentinas foram nos campos da engenharia de reatores de pesquisa, em que aquele país tornouse referência mundial. Mesmo no campo dos reatores de potência a Argentina desenvolveu um projeto de reator enriquecido e água leve, de pequeno porte. Houve ainda desenvolvimento significativo no ciclo de combustível, inteiramente dominado com tecnologias próprias, e no desenvolvimento de aplicações, sobretudo na área médica, inclusive com o projeto e fabricação de equipamentos para aplicação de radioisótopos.

Subentende-se uma implícita disputa tecnológica entre Brasil e Argentina durante seus respectivos regimes militares. O receio e insegurança, naturais em questões de trato sensível como o desenvolvimento nuclear, geraram a justificativa de criação e prosseguimento de seus programas nucleares que, apesar do medo de uma possível corrida armamentista na América Latina, caminhou para um contexto pautado pela cooperação técnica e política. Além disso, no ambiente internacional, a construção de alternativas energéticas tornara-se um forte aliado de qualquer iniciativa que representasse diversificação de fontes energéticas. 


\section{CAPÍTULO 3 \\ Aproximação na política nuclear da Argentina e do Brasil}

A possibilidade de um conflito entre Brasil e Argentina era seriamente considerada pelas cúpulas militares e políticas dos dois países, entre 1920 e 1940. Inúmeras estratégias foram formuladas voltadas para um cenário de exacerbação da rivalidade histórica, fundamentadas na suposta inevitabilidade de uma virtual deflagração de um conflito armado entre os dois lados. Entretanto, a partir de 1945, o desenvolvimento da tecnologia nuclear proporcionou uma mudança qualitativa nas possíveis conseqüências dessa rivalidade. Um novo elemento surgia - a bomba nuclear - e, com ele, emergia também o perigo de uma corrida armamentista que poderia desencadear uma catástrofe irreversível para a região.

$\mathrm{Na}$ década de 50, ambos os países engajaram-se numa disputa pelo status de país mais desenvolvido na área nuclear; isso porque de acordo com o Artigo VI, parágrafo A, inciso I, do Estatuto da Agência Internacional de Energia Atômica (AIEA), de 1956, integraria a Junta de Governadores o membro mais adiantado na tecnologia da energia atômica em cada região. Como a América Latina é uma dessas regiões, criou-se o cenário para uma disputa entre os dois países pela designação de "membro mais adiantado", mas essa situação acabou sendo resolvida com um acordo de cavalheiros entre os dois países, com a anuência da Junta de Governadores: Brasil e Argentina ocupariam rotativamente o posto da região, enquanto que, no mesmo período, o outro integraria a Junta como "membro eleito".

Como um gesto de aproximação, a Argentina expressou, publicamente, ser favorável ao acordo nuclear assinado entre Brasil e Argentina 
em 1975, acordo este que estava sendo alvo de fortes críticas dos Estados Unidos. Ainda assim, aos poucos foram sendo estabelecidos contatos entre os organismos dos dois países (Brasil e Argentina) com atividade na área nuclear. A idéia de um acordo de integração entre esses países foi amadurecida com o passar do tempo, e os estudos iniciais para este acordo incluíram avaliação geral dos programas nucleares do Brasil e da Argentina para que fossem definidos os possíveis pontos de cooperação. Ademais, a segunda crise do petróleo, ocorrida em 1979, fez surgir um grande entusiasmo geral pela possibilidade e pelas perspectivas de aplicação da energia nuclear. As possibilidades de cooperação entre Brasil e Argentina aumentaram quando, após a segunda metade da década de 70, houve rápidos avanços no programa nuclear brasileiro, motivados, basicamente, pela crise anteriormente citada.

Durante a visita do presidente João Batista Figueiredo a Buenos Aires, em 17 de maio de 1980, foi assinado o documento que marcou oficialmente o início do processo de cooperação na área da tecnologia nuclear. O Acordo de Cooperação para o Desenvolvimento e Aplicação dos Usos Pacíficos da Energia Nuclear, assinado pelo presidente Figueiredo e pelo presidente argentino, Jorge Rafael Videla, estabelecia o intercâmbio tecnológico e definia modalidades de assistência recíproca para a formação de cientistas, permuta de técnicos e professores, além da criação de grupos mistos de trabalho. Os dois países reiteravam que seus programas nucleares tinham fins exclusivamente pacíficos e que eram contrários à fabricação de armas nucleares.

Cinco anos depois, foi assinada a Declaração Conjunta sobre Política Nuclear, também conhecida como Declaração de Iguaçu. Tal ato ocorreu durante a cerimônia de inauguração da ponte que liga as cidades fronteiriças de Porto Meira e Puerto Iguazu. Nessa Declaração, os presidentes José Sarney e Raul Alfonsín reafirmaram os compromissos na área da tecnologia nuclear 
anteriormente acordados, criando, inclusive, um Grupo de Trabalho Conjunto, sob a responsabilidade das chancelarias de ambos os países.

O Grupo de Trabalho era integrado por representantes da Comissão Nacional de Energia Nuclear - CNEN, brasileira - e da Comissão Nacional de Energia Atômica - CNEA, argentina. Incluía também representantes de empresas atuantes na área de comércio de material nuclear. O objetivo do grupo era fomentar as relações entre os dois países na área nuclear, promover o seu desenvolvimento tecnológico e criar mecanismos que garantissem a paz, a segurança e o desenvolvimento da região.

A Declaração de Iguaçu originou novo ciclo no processo de cooperação nuclear. O início da aproximação foi oficialmente consolidado com o Programa de Integração e Cooperação Econômica entre Argentina e Brasil (PICAB), firmado em julho de 1986. A partir desse marco formal, foram assinados 22 protocolos entre 1986 e 1988. Nesse período, foram aprofundados acordos de preferências tarifárias, estimulada a formação de empresas binacionais, criados comitês em áreas de fronteiras e assinados acordos de cooperação científica e tecnológica, nas áreas da tecnologia nuclear e da pesquisa aeroespacial.

Com o intuito de aprofundar o processo geral de cooperação, os presidentes Sarney e Alfonsín assinaram, em julho de 1986, doze protocolos que constituíram a primeira fase do PICAB. Dez deles referiam-se a trocas comerciais, um sobre cooperação nuclear - criando sistema de informação imediata e assistência recíproca em casos de acidentes nucleares e emergências radiológicas - e um relativo a cooperação para fabricação de partes de aviões brasileiros na Argentina.

No final daquele ano, mais precisamente no dia 10 de dezembro, os dois presidentes assinaram a Declaração Conjunta de Política Nuclear, 
conhecida como Declaração de Brasília. A Declaração ratificava os termos da Declaração de Iguaçu e estimulava a participação empresarial em projetos industriais no setor nuclear.

No decorrer dos anos, outros acordos bilaterais foram assinados. Um dos mais significativos foi a Declaração Conjunta sobre Política Nuclear, durante a inauguração da Unidade de Enriquecimento de Urânio Almirante Álvaro Alberto, em 8 de abril de 1988. Conhecida como Declaração de Iperó, ela transformou o antigo Grupo de trabalho Conjunto, criado pela Declaração de Iguaçu, em Comitê Permanente, que deveria se reunir a cada 120 dias, alternadamente em cada país, para tratar de assuntos nucleares.

Nessa declaração, os dois países reiteraram seu direito de desenvolver, sem restrições, programas nucleares para fins pacíficos, manifestaram que o conhecimento recíproco desses programas seria a base do aprofundamento da cooperação política e técnica, e demonstraram o desejo de estender tal cooperação a outros países, com o objetivo de integrar toda a América Latina em direção da unidade, confiança e modernidade.

O processo de integração avançava, mas ainda baseado em declarações conjuntas. Era preciso assinar um tratado para que o compromisso entre dois presidentes se transformasse formalmente em um compromisso entre os dois países. Em novembro de 1988, os presidentes Sarney e Alfonsín assinaram o Tratado de Integração, Cooperação e Desenvolvimento, que representou a consolidação legal do processo de integração nuclear assinado em 1980. John R. Redick, no Seminário sobre Salvaguardas Regionais na América Latina ${ }^{26}$, assim avalia a cooperação Argentina-Brasil:

Sin embargo, el regreso a gobiernos democráticos en Argentina y Brasil, aceleró y profundizó el acercamiento nuclear. Bajo gobiernos democráticos desde mediados de los

${ }^{26}$ Revista Occidental - Estudios Latinoamericanos. Año 15, Numeros 1 y 2, p. 9. 
80, los asuntos económicos y comerciales asumieron mayor importancia, por primeira vez en sus 150 años de historia, comenzó un progreso real hacia un área libre de comercio en el Cono Sur y la cooperación política fue posible para los dos históricos rivales.

O passo seguinte na integração foi dado com a adoção de acordos de fiscalização mútua. Em 28 de novembro de 1990, em Foz do Iguaçu, os presidentes Fernando Collor de Mello e Carlos Saúl Menem assinaram a Declaração sobre Política Nuclear Comum, conhecida como Declaração Conjunta de Fiscalização Mútua. Nela, em um nítido salto qualitativo em termos de integração nuclear, ficou decidido:

1) Aprovar o Sistema Comum de Contabilidade e Controle (SCCC) apresentado pelo Comitê Permanente, aplicado a todas as atividades nucleares dos dois países;

2) Fornecer as respectivas listas descrevendo todas as instalações nucleares;

3) Fazer a permuta das declarações dos inventários iniciais dos materiais nucleares existentes em cada país;

4) Realizar as primeiras inspeções recíprocas aos sistemas centralizados de registros;

5) Apresentar à AIEA o sistema de registros e relatórios do SCCC;

6) Abrir negociações com a AIEA com o objetivo de firmar acordo conjunto de salvaguardas que tenha como base o SCCC;

7) Concluir o acordo de salvaguardas com a AIEA, possibilitando a vigência do Tratado para Proscrição de Armas Nucleares na América Latina (Tratado de Tlatelolco).

Com a Declaração Conjunta de Fiscalização Mútua pretendia-se pôr fim à antiga rivalidade militarista entre vizinhos. Os dois países também enfatizavam a renúncia de promover qualquer tipo de explosão de artefatos nucleares em seus territórios. A declaração ainda criava sistema conjunto de controle contábil de material nuclear que possibilitava a inspeção mútua das atividades e da produção nuclear. A idéia era proporcionar às duas nações informações sobre a quantidade exata de material atômico de cada lado, seu destino e localização. O objetivo último era impedir o desenvolvimento de programas nucleares secretos, sem fiscalização internacional. 
A declaração precisava ser transformada em instrumento jurídico ratificado pelos respectivos Congressos. Assim, durante a I Reunião de Cúpula dos Países Íbero-Americanos, realizada em Guadalajara, no México, os presidentes Collor e Menem assinaram um novo documento: o Acordo para Uso Exclusivamente Pacífico da Energia Nuclear. Pelo citado acordo, os países se comprometiam a proibir e a impedir em seus territórios, bem como absterse de realizar, fomentar ou autorizar, direta ou indiretamente, ou de participar de qualquer maneira, em teste, uso fabricação, produção ou aquisição, por qualquer meio, de toda arma nuclear, e na recepção, armazenamento, instalação, colocação ou qualquer forma de posse de qualquer arma nuclear. ${ }^{27}$

O documento deixa em aberto a possibilidade de uso da energia nuclear para propulsão ou operação de qualquer tipo de veículo, incluindo submarinos, por entender tratar-se de formas de uso pacífico dessa fonte de energia. Também estabelece a cada Estado-parte o direito inalienável ao desenvolvimento da pesquisa, produção e uso da energia nuclear com fins pacíficos, preservando segredos industriais, tecnológicos e comerciais. Pelo acordo, os dois países devem submeter os materiais atômicos usados em todas as atividades nucleares realizadas em seus territórios, ou sob sua jurisdição ou controle, ao SCCC. Para administrar e aplicar o SCCC, as partes criaram a Agência Brasileiro-Argentina de Contabilidade e Controle de Materiais Nucleares (ABACC). Esta Agência viria a fortalecer o sistema de cooperação e aumentar o grau de confiança da comunidade internacional em relação aos programas nucleares dos dois países e, dessa forma, facilitar o acesso a tecnologias avançadas. O Relatório Anual da ABACC, de 2006 destaca:

Em várias oportunidades, a importância do trabalho da ABACC foi destacada por representantes do Brasil e da Argentina, particularmente, na Conferência Geral da AIEA e durante a visita à Argentina do Ministro das Relações

\footnotetext{
${ }^{27}$ Acordo entre República Federativa do Brasil e a República Argentina para Uso Exclusivamente Pacífico da Energia Nuclear, de 18 de julho de 1991.
} 
Exteriores do Brasil, Embaixador Celso Amorim, a convite do Chanceler Jorge Enrique Taiana, para a celebração do 15 aniversário da criação da ABACC. Nessa cerimônia, realizada no Ministério das Relações Exteriores, Comércio Internacional e Culto da Argentina, foi assinada a Declaração Conjunta que reconhece a instituição como instrumento de transparência e aproximação bilateral na implementação de salvaguardas e no cumprimento do compromisso com a não-proliferação, oferecendo garantias às sociedades de ambos os países e à comunidade internacional em relação aos usos pacíficos da energia nuclear tanto no Brasil como na Argentina. ${ }^{28}$

Único no mundo, esse gênero de arranjo regional de controle constitui um exemplo único de cooperação entre dois países quanto ao diálogo e à vontade de progredir num setor sensível por meio do entendimento mútuo. Em grande medida, pode-se dizer que confirmam o pressuposto das sabedorias antigas que ensinam que a união e a amizade são fatos que agregam inúmeros valores e ampliam as possibilidades.

É preciso observar que, em território nacional, até 1989, as atividades nucleares mais sensíveis ainda estavam livres de qualquer tipo de salvaguarda. O sistema nacional de salvaguardas era até então aplicado somente aos materiais e equipamentos transferidos no âmbito dos acordos bilaterais de cooperação com a Alemanha e os Estados Unidos. Tais materiais e equipamentos estavam sujeitos a acordos de salvaguardas parciais com a AIEA (acordos trilaterais do tipo INFCIRC/66), e esses materiais não poderiam ser utilizados para quaisquer fins militares. Assim, no Brasil, a criação do SCCC teria servido também para aumentar o controle civil sobre instalações operadas por militares.

Atualmente, existem dois tipos de acordos de salvaguardas entre os países não-nuclearmente armados e a AIEA - tais acordos são batizados a partir dos documentos que contêm esses modelos. Além dos acordos parciais (ou trilaterais), do tipo INFCIRC/66, existem os acordos abrangentes, do tipo 
INFCIRC/153, aplicados a todos os materiais nucleares presentes em todas as atividades realizadas pelo Estado-parte. Nos dias de hoje, acordos do tipo INFCIRC/66 vigoram apenas para países não-partes do Tratado de NãoProliferação (TNP). Os acordos do tipo INFCIRC/153, por sua vez, são válidos para todos os países não-nucleares partes do TNP, tendo sido modificados em parte no caso dos países que não possuem armas nucleares da Comunidade Européia de Energia Atômica (Euratom) - a INFCIRC/193 ${ }^{29}$, em vigor desde 1977 - e, no caso do Acordo Quadripartite, entre Brasil, Argentina, ABACC e AIEA.

Além desses dois tipos de acordos de salvaguardas básicos da AIEA, há o chamado acordo de "oferta voluntária", aplicável apenas a certas instalações de programas nucleares civis das cinco potências nucleares, assim definidas pelo TNP. Note-se a diferença de tratamento: cabe apenas aos cinco países em questão escolher individualmente quais de suas instalações poderão ser objeto de salvaguardas. Ficam assim descobertas todas as atividades de caráter militar desenvolvidas por esses países.

A aplicação de salvaguardas tradicionais do TNP está associada a materiais fonte ou físseis especiais, e não sobre instalações nucleares. As possibilidades de aplicação dessas salvaguardas estão centradas principalmente na contabilidade e controle de material nuclear, o que facilitou muito sua aceitação por parte dos países não-nuclearmente armados membros do TNP. Estes consideraram, em linhas gerais, tal tipo de verificação menos intrusivo do que a verificação de instalações ligadas ao ciclo de combustível nuclear.

Outro ponto do Acordo assinado em Guadalajara que merece ser destacado é o compromisso das Partes no sentido de proibir qualquer dispositivo nuclear explosivo, mas apenas enquanto existir a impossibilidade de

\footnotetext{
29 Aprovada pela Junta de Governadores da AIEA em 1973, esta INFCIRC foi negociada pela Comunidade Européia antes da ratificação do TNP pelos seus membros, fato ocorrido em 1975.
} 
distinção técnica entre "dispositivos nucleares explosivos para fins pacíficos" e aqueles "destinados a fins bélicos". A ambigüidade presente no Artigo I a respeito das explosões nucleares parece estar relacionada à resistência argentina em abrir mão completa e claramente desse tipo de explosões no futuro - a posição brasileira em relação ao tema teria evoluído mais rapidamente. O fato é que o citado dispositivo deixaria de ter relevância no Acordo Quadripartite, que proíbe a realização de explosões nucleares, sem qualificá-las.

Além disso, o Acordo de Guadalajara já incluía, no campo bilateral, os principais pontos de interesse das Partes em relação à preservação de informações estratégicas (segredos industriais, tecnológicos e comerciais, como disposto no Artigo II) e a manutenção das opções nacionais relacionadas a explosões nucleares pacíficas (com ressalvas) e ao desenvolvimento da propulsão nuclear naval (artigo III).

\section{O ACORDO QUADRIPARTITE}

Em 13 de dezembro de 1991, na sede da Agência Internacional de Energia Atômica, em Viena, foi assinado um Acordo Quadripartite, de salvaguardas abrangentes, embora não totais. Este Acordo tem como Partes a República Federativa do Brasil, a República Argentina, a Agência BrasileiroArgentina de Contabilidade e Controle de Materiais Nucleares e a própria AIEA. $^{30}$

Com este passo, ambos os países reverteram a política nuclear de mais de quatro décadas e abriram mão das pretensões de tornarem-se potências atômicas regionais. Pelo acordo, Brasil e Argentina submetem seus programas

\footnotetext{
${ }^{30}$ No Brasil, o Acordo foi aprovado pelo Senado Federal no dia 9 de fevereiro de 1994, publicado no Diário Oficial da União no dia 25 de fevereiro de 1994 e sancionado pelo presidente Itamar Franco em 4 de março daquele ano.
} 
nucleares ao controle internacional, colocando sob vigilância todas as instalações e materiais nucleares. O Acordo Quadripartite é um instrumento sui generis, que reproduz em larga medida as disposições presentes nos acordos de salvaguardas totais que a AIEA assina com os Estados-partes do Tratado de Não-Proliferação Nuclear (TNP). Paradoxalmente, nessa época, os dois países recusavam-se a aderir ao TNP.

Este acordo bilateral de controle de armas nucleares foi levado a cabo com êxito no contexto de uma melhora de vários fatores na relação bilateral, principalmente no que tange aos aspectos econômicos, políticos e militares em todo o Cone Sul. Sem embargo, uma lição importante trazida por essa experiência é a de que os acordos internacionais mesmo em campos sensíveis não precisam, necessariamente, aguardar a evolução de outros assuntos políticos. Pelo contrário, as lideranças políticas (civis e militares) usaram o progresso bilateral no campo nuclear como um catalisador para estimular e reforçar a cooperação em outras áreas. Também é possível depreender desses fatos que uma liderança política esclarecida pode utilizar-se do simbolismo inerente ao tema nuclear para estimular e evoluir com a pauta de outras áreas. O progresso nuclear e sua coordenação não precisam esperar pela resolução de todos os outros assuntos importantes, ao contrário, podem servir para dar-lhes impulso.

Pelo acordo, mesmo a exportação de material nuclear pelos dois países é rigorosamente controlada. Qualquer transporte superior a um quilo de material nuclear deve ser notificado à AIEA. O acordo também prevê o uso de material nuclear para propulsão ou operação nuclear de qualquer veículo, inclusive submarinos ou protótipos, ou em atividades nucleares não-proscritas acordadas entre as Partes e a AIEA (Artigo 13).

Antes da entrada em vigor do Acordo Quadripartite, o Brasil estava comprometido com dois acordos de salvaguardas da AIEA, do tipo 
INFCIRC/66, chamados trilaterais: um com os Estados Unidos (INFCIRC/110) e outro com a República Federal da Alemanha (INFCIRC/237). A assinatura dos acordos havia sido exigência dos dois países com os quais havíamos assinado acordos bilaterais de cooperação. Por meio de tais acordos por instalação, também chamados de aplicação parcial, o material e o equipamento de determinada instalação ficam sob salvaguardas, sem poder ser transferidos para outra instalação. No caso de transferência, ocorre a chamada "contaminação de salvaguardas" - o material e o equipamento transferidos para uma instalação salvaguardada passam, de igual forma, a ser alvo de fiscalização, e vice-versa.

Com a assinatura do Quadripartite, os dois acordos supracitados foram suspensos, uma vez que este possui uma cláusula nesse sentido. Comparativamente, a suspensão do acordo trilateral com os EUA e a AIEA (em 22 de outubro de 1996) foi mais fácil - o acordo bilateral já incluía uma cláusula que proibia o uso de qualquer material ou equipamento para fins militares. No caso do acordo com a Alemanha, o processo de suspensão foi mais demorado, porque o acordo bilateral não continha cláusulas de proibição de usos para fins militares, apenas para fins explosivos. Pelo acordo de 1975, o Brasil se comprometia apenas a não utilizar o material ou equipamento transferidos para fins explosivos ou de produção de armas nucleares.

Pelo acordo trilateral posterior, de 1976, o compromisso brasileiro era de não utilizar material ou equipamento para produção de armas nucleares, para produção de qualquer artefato nuclear explosivo ou para qualquer outro fim militar. Por este motivo, houve resistência por parte da Alemanha para autorizar a suspensão do acordo trilateral, considerando-o mais restritivo do que o acordo de 1975 e do que o próprio Quadripartite. A INFCIRC/237 foi finalmente suspensa em 21 de outubro de 1999, mas apenas depois da inclusão, na parte preambular do Protocolo de Suspensão, de linguagem que reporta ao 
dispositivo do acordo trilateral relacionado à proibição para quaisquer fins militares.

Tanto na Argentina quanto no Brasil, algumas salvaguardas parciais do modelo INFCIRC/66 já eram aplicadas a algumas instalações. Por meio deste Acordo, os países-membro se comprometem a aceitar a aplicação de salvaguardas internacionais sobre todas as atividades nucleares levadas a efeito dentro de seus territórios ou de qualquer lugar sob sua jurisdição ou controle, com o propósito único de certificar-se de que tais materiais não sejam desviados para armas nucleares ou outros artefatos nucleares explosivos.

Para tanto, a AIEA está habilitada a certificar-se de que as salvaguardas sejam aplicadas segundo os termos do Acordo, em todas as atividades nucleares. Paralelamente, a ABACC se compromete a aplicar suas salvaguardas sobre materiais nucleares em todas as atividades nucleares desenvolvidas nos territórios dos países membros e a cooperar com a AIEA em conformidade com os termos acordados. A AIEA aplica suas salvaguardas de maneira a permitir a verificação dos resultados do SCCC e, assim, garantir que não tenha ocorrido nenhum desvio de material nuclear. A verificação dessa Agência inclui mensuração e observações independentes, de acordo com os procedimentos especificados no acordo. Em sua verificação, a AIEA deve considerar a eficácia técnica do SCCC utilizado pela ABACC.

O Acordo Quadripartite determina que a AIEA e a ABACC devem evitar duplicações desnecessárias de atividades ligadas a salvaguardas, e inclui um protocolo especificando os dispositivos sobre cooperação na aplicação de salvaguardas. Segundo esse protocolo, a ABACC e a AIEA devem tirar conclusões independentes e trabalhar em conjunto, sempre que possível. Toda possível anomalia é investigada. Caso seja confirmada alguma situação anormal, a ABACC notifica a parte correspondente e solicita a regularização da situação. Caso não ocorra regularização, pode ficar caracterizado descumprimento grave 
do Acordo. Nesse caso, a outra parte tem o direito denunciar o Acordo ou suspender sua aplicação, total ou parcialmente, cabendo-lhe ainda notificar tal fato ao secretário-geral das Nações Unidas e ao secretário-geral da Organização dos Estados Americanos (OEA).

Algumas conclusões emergem da análise do papel do regime de nãoproliferação no comportamento do Brasil e da Argentina. Antes da década de 90, os dois países sofriam fortes pressões internacionais, consubstanciadas principalmente no Tratado de Não-Proliferação (TNP). Depois da assinatura do Quadripartite, passos sucessivos foram dados em direção à adesão total ao regime de não-proliferação.

A criação de um acordo sub-regional certamente facilitou a adesão a tratados de alcance regional, como o Tratado de Tlatelolco, e global, como o próprio TNP. A experiência dos dois países indica constituir equívoco recusar acordos regionais com base em argumentos de que eles desvirtuam os regimes globais. Ao contrário, o exemplo dado pelos dois países em questão sugere que a adesão a um regime global pode ser amplamente facilitada por uma aproximação prévia de rivais regionais. A experiência indica que onde há confiança entre rivais torna-se muito mais fácil a adoção de um regime de controle. Nesse caso, o papel do regime de não-proliferação - atuando como variável interveniente entre o poder e o contexto de segurança, de um lado, e o comportamento dos dois países no jogo nuclear, do outro - parece ter aumentado de importância depois que este regime foi consolidado no ambiente sub-regional.

Essa importância traduziu-se no aumento dos constrangimentos às ações de ambos os países no campo nuclear. Depois do Acordo Quadripartite, não apenas ficou mais difícil para o Brasil e Argentina adotarem ações em direção a uma eventual fabricação de um artefato nuclear, como aumentaram as dificuldades, até mesmo em termos de coerência lógica, de manter um 
posicionamento contrário à não-proliferação na esfera internacional, e de recusar o TNP bem como a entrada em vigor do Tratado de Tlatelolco.

A ratificação do Tratado para o Banimento Completo de Testes Nucleares (Comprehensive Nuclear-Test Ban Treaty - CTBT) e a ausência, nos últimos anos, de mudanças significativas no comportamento dos dois países em relação ao tema nuclear corroboram essa hipótese. A eventual aceitação conjunta do Protocolo Adicional (instrumento que obriga os Estados signatários a aceitar a aplicação de salvaguardas sobre atividades que não envolvem material nuclear) viria a confirmar tal tendência.

Assim posto, o sistema de controle recíproco foi visto não somente como um requisito indispensável para afirmar a confiança mútua entre Brasil e Argentina, mas também como uma "condição sine qua non" para produzir confiança na sociedade internacional. Em outras palavras, os dois países poderiam se conformar com um sistema fraco de geração de confiança, decidindo que os mecanismos existentes até 1989 bastavam para preservar sua segurança. Mas os que provavelmente não se conformariam seriam os outros países, vizinhos ou não, principalmente aqueles que se consideravam guardiões da segurança internacional e da não-proliferação nuclear, como os Estados Unidos.

São justamente as considerações sobre o poder e o contexto de segurança que parecem ter influenciado a mudança de atitude brasileira e argentina em relação à aceitação de salvaguardas e ao regime de nãoproliferação. Mas, uma vez aceito o regime, a situação apresenta notáveis mudanças. Os constrangimentos impostos pelo regime, ou seja, sua influência no comportamento dos dois países, parece ter aumentado. A conseqüência imediata dessa mudança é o aumento nos custos de uma possível guinada nesse comportamento em direção a atitudes de repúdio ao regime de nãoproliferação. 
Como destaca Keohane ${ }^{31}$, a principal função dos regimes existentes é reduzir as incertezas e a insegurança no ambiente internacional. Assim, regimes servem: para estabilizar expectativas mútuas relacionadas ao comportamento futuro dos outros Estados; reduzir os custos de transação; produzir informação que de outra maneira não estaria disponível ou estaria disponível somente com alto custo; e proporcionar um quadro de referência que garante a freqüente repetição das interações.

${ }^{31}$ KEOHANE, Robert O. After Hegemony - Cooperation and Discord in the World political economy. Princeton, N. J. Princeton University Press. 1984. Capítulo 7. 


\section{Conclusão}

Desde o dramático evento do lançamento das duas bombas atômicas sobre o Japão, em 1945, o medo, a paixão e o segredo estiveram associados à questão nuclear. Algo compreensível, dado o potencial uso dual dessa tecnologia e o conhecido poder de destruição das armas nucleares aperfeiçoadas a cada dia, vale lembrar - com essa característica. $\mathrm{Na}$ impossibilidade de que tal tecnologia seja "desinventada", o tema certamente permanecerá tendo expressiva relevância na agenda internacional. Por suas implicações, trata-se de questão essencialmente de caráter multilateral, para o qual não existem soluções isoladas. O sensacionalismo contribui para tornar ainda mais difícil a análise de assunto tão complexo, com suas vertentes militares, econômicas, políticas, legais e ambientais. Na afirmação de Graham Allison, "on the current course, nuclear terrorism is inevitable. (...) The good news about nuclear terrorism is that this ultimate catastrophe is, in fact, preventable. "\$2

Atento às possibilidades de aplicação pacífica da nova tecnologia, aos poucos, com altos e baixos, o Brasil buscou desenvolver seu programa nuclear. Por meio de acordos de cooperação, assinados primeiro com os Estados Unidos, e depois com a Alemanha Ocidental, construiu duas usinas nucleares (Angra I e Angra II) e buscou a transferência de tecnologia e o desenvolvimento de uma indústria nuclear própria. Com esse propósito, nos dois últimos governos militares, desenvolveu um programa secreto e paralelo, fora do alcance das salvaguardas internacionais. Tal processo culminou com o domínio completo do ciclo do combustível, anunciado em 1987, já tendo no Brasil um governo civil.

32 ALLISON, Graham. Nuclear Terrorism. Times Books. New York, 2004, p. 203-204. 
Paralelamente ao interesse brasileiro por essa tecnologia, consolidouse, nos anos de 1960, um grande esforço internacional para impedir a proliferação de armas nucleares, capitaneado pelos Estados Unidos e pelas novas potências que haviam logrado produzir tais armas. Para um país como o Brasil, que, ao lado da Argentina, manteve durante muitos anos uma postura crítica em relação ao regime de não-proliferação nuclear - posição esta permeada por uma certa ambigüidade em defesa do direito de promover explosões nucleares "para fins pacíficos" -, a adesão, na década de 1990, aos principais tratados internacionais relacionados ao tema não significou o fim das pressões externas sobre sua política nuclear.

A evolução da posição brasileira em relação à não-proliferação teve como ponto alto o processo de integração nuclear com a Argentina, acompanhado de um processo mais amplo de integração econômica e política. A inserção conjunta de ambos os países no regime internacional, por meio do Acordo Quadripartite, abriu caminho para a adesão e entrada em vigor do Tratado de Tlatelolco, a ratificação do CTBT e a adesão ao TNP. Ao longo desse caminho, o Brasil sempre reafirmou suas credenciais pacíficas e buscou o desenvolvimento de seu programa nuclear.

No contexto atual, em linhas gerais, por uma questão de coerência com sua política nos últimos anos, o Brasil deve sempre considerar o relacionamento com a Argentina, em sua busca para assegurar o acesso a bens e tecnologias de caráter estratégicos, bem como os compromissos já assumidos na área da não-proliferação e os esforços internacionais em direção ao desarmamento nuclear.

Pode-se dizer que o regime de não-proliferação não foi fator determinante no comportamento tanto do Brasil quanto da Argentina no que tange às suas políticas nucleares, uma vez que por longo período ambos os países conseguiram resistir com relativo sucesso às pressões para a aceitação de 
salvaguardas para seus programas nucleares. Assim, a pressão externa não parece ter sido uma das principais razões para a mudança; políticas de restrição de exportação de tecnologia por parte dos países mais desenvolvidos teriam antes reforçado o sentimento de vitimização do Brasil e da Argentina. Até a década de 90, as decisões dos dois países estiveram nitidamente mais associadas a considerações de poder e ao contexto de segurança.

Mantidas as condições atuais, pode-se dizer com considerável grau de certeza que é improvável uma reviravolta no comportamento de ambos os países na questão nuclear em direção ao desenvolvimento de armas nucleares. Essa atitude, de qualquer um dos lados, representaria o fim do regime e a desestabilização das expectativas mútuas relacionadas ao comportamento futuro do vizinho.

Diante do que precede, é notável e até exemplar a disposição brasileira em cultivar uma política pacifista no campo nuclear com nossos vizinhos argentinos, política essa que certamente serve de exemplo para uma aproximação mais consistente em outros temas. Por conta das iniciativas bilaterais, os prospectos de se evitar a disseminação de armas nucleares na América Latina são mais favoráveis atualmente do que jamais foram, desde o desenvolvimento da energia nuclear.

Assim sendo, a cooperação nuclear foi uma opção e se deu em virtude do redesenho geopolítico mundial que ocorreu após a queda da União Soviética, somado à ascensão de governos democráticos no Brasil e Argentina, encerrando assim as ditaduras militares. Além disso, apesar do senso comum acerca da rivalidade entre Brasil e Argentina, nota-se que na história de ambos os países houve uma forma de consenso velado acerca do interesse em evitar a marginalização diante da hegemonia americana e das vicissitudes da política mundial, face às tentativas de desenvolvimento nuclear praticadas por sucessivos governos tanto no Brasil quanto na Argentina. Diante da evolução 
da questão nuclear nesses dois países parece razoável a idéia de que apenas usufruindo de cooperação seria possível adotar práticas relevantes após insucessos também compartilhados. 


\section{REFERÊNCIAS BIBLIOGRÁFICAS}

ALLISON, Graham. Nuclear Terrorism. Times Books. New York, 2004.

AMORIM, Celso. Rumo a um mundo livre de armas nucleares: o significado de um "compromisso inequivoco". In: Política Externa, vol. 9, n. 3, dezembro, janeiro e fevereiro de 2000/2001. São Paulo. Editora Paz e Terra, 2001.

ART, Robert \& WALTZ, Kenneth. The use of force: military power and international politics. Brasília: Editora Universidade de Brasília, 1981.

BATISTA, Paulo Nogueira. "O acordo nuclear Brasil-República Federal da Alemanha". In: Sessenta Anos de Política Externa Brasileira 1930-1990: Vol. 4. NUPRI/USP, 2000.

BRASIL. Agência Brasileiro-Argentina de Contabilidade e Controle de Materiais Nucleares. Relatório Anual 2006.

BRASIL. Agência Brasileiro-Argentina de Contabilidade e Controle de Materiais Nucleares. Relatório Anual 2007.

BULL, Hedley. A Sociedade Anárquica. Brasília: Universidade de Brasília, 2002.

CARASALES, Julio Cesar. De rivales a socios: el processo de cooperación nuclear entre Argetina e Brasil. Buenos Aires. Nuevohacer. Grupo Editor Latinoamericano, 1997.

CERVO, Amado e BUENO, Clodoaldo. História da Política Exterior do Brasil. Coleção "O Brasil e o Mundo". Editora UnB/IBRI. 2a edição. Brasília, 2002.

JERVIS, Robert. Realism, Neoliberalism and Cooperation. New York: Cornell University Press, 1983.

KEOHANE, Robert O. After Hegemony - Cooperation and Discord in the World political economy. Princeton, N. J. Princeton University Press, 1984.

KEOHANE, Robert O.; NYE, Joseph S. Power and Interdependence. Nova Iorque: Longman, 2001.

KIRSCHBAUM, Ricardo. Brasil, Argentina y el uranio. Jornal Clarín, 29 de novembro de 2004.

NYE, Joseph. The Paradoxof Amercian Power: Why the World's Only Superpower Can't Go It Alone. Oxford and New York: Oxford University Press, 2003.

OLIVEIRA, Eliézer Rizzo de. Segurança e defesa nacional - da competição à cooperaşão regional. São Paulo. Fundação Memorial da América Latina, 2007.

Revista Occidental - Estudios Latinoamericanos. Año 15, Numeros 1 y 2.

SCHWARTZMAN, Simon Um Espaço para a Ciência - A Formação da Comunidade Científica no Brasil de autoria de (MCT/CEE, Brasilia, 2001). 
SKIDMORE, Thomas E. Brasil: de Castelo a Tancredo. Rio de Janeiro. Editora Paz e Terra, 1988.

SPECTOR, Leonard S. The undeclared bomb - the spread of nuclear weapons 1987-1988.

Cambridge, Massachusetts. Carnegie Endowment for International Peace, 1988.

TOMALSQUIM, Alfredo Tiommo, Einstein - O Viajante da Relatividade na América do Sul. Editora Vieira \&Lent, 2003.

WROBEL, Paulo. "A política nuclear brasileira". In Sessenta Anos de Politica Externa Brasileira 1930-1990: Vol. 4. NUPRI/USP, 2000.

\section{Sites na internet}

http://disarmament2.un.org/cd (Conferência de Desarmamento da ONU) http://www.anvisa.gov.br (Anvisa) www.ctbto.org (Comprehensive Nuclear-Test Ban Treaty Organization) www.iaea.org (Agência Internacional de Energia Atômica) www.iiss.org (International Institute for Strategic Studies) www.mct.gov.br (Ministério da Ciência e Tecnologia) www.mre.gov.br (Ministério das Relações Exteriores) www.nam.gov.za (Movimento Não-Alinhado) www.nuclearsuppliersgroup.org (Grupo de Supridores Nucleares) www.reachingcriticalwill.org www.un.org (Organização das Nações Unidas) 